\title{
PSYCHOSOCIAL HAZARDS AND RISKS IN THE CONSTRUCTION INDUSTRY IN NEW SOUTH WALES, AUSTRALIA
}

\author{
Negar Rezaeian', Liyaning Tang ${ }^{2}$ and Mary Hardie ${ }^{3}$
}

\begin{abstract}
The construction industry faces many challenges, one of which is the difficult to define psychosocial influences. The construction sector has highly demanding employment conditions, long working hours and sometimes unfeasible terms of project execution. Psychosocial influences represent emotional as well as physiological characteristics which impact the immediate environment. Some construction personnel face psychosocial problems that can lead to depression or suicide. The research conducted in this paper focuses on the psychosocial status of personnel working in construction companies, in New South Wales (NSW), Australia. A questionnaire survey was conducted to investigate the psychosocial hazards observed in the construction industry in NSW. Practitioners in two private construction companies and one government department having construction project management experience in NSW were involved in the survey. The data analysis indicates that most workers experienced being pressured to stay back and work long hours. This led to workers being 'very frequently' tired. Regarding bullying, Respondents reported that the frequency of they experienced 'exclusion or isolation from workplace activities' was 'monthly'. Being 'Subjects of gossip or false, malicious rumours' was reported as happening 'weekly' and 'Humiliation through gestures, sarcasm, criticism or insults' was said to happen 'almost daily'. This study's findings indicate that construction projects could have unaddressed psychosocial hazards and risks, each of which may be a potential factor for accidents and occupational and psychological injuries. The data displayed from this research could help understand psychosocial hazards. Spreading awareness on the issue can hopefully be a step towards improving the mental health of construction workers while decreasing the overall suicide rate.
\end{abstract}

Keywords: Australia; Construction industry; Mental health; New South Wales; Psychosocial hazards.

\section{INTRODUCTION}

Construction is probably one of the oldest occupations in history. However, it still presents a formidable challenge to health and safety experts with its lengthy background. Despite concerted efforts and significant workplace health and safety improvements, the construction industry remains one of the most hazardous sectors with serious injuries.

\footnotetext{
${ }^{1}$ School of Engineering, Design and Built Environment, Western Sydney University, NSW Australia, 19221986@student.westernsydney.edu.au

${ }^{2}$ School of Architecture and Built Environment, The University of Newcastle, NSW, Australia, Maggie.Tang@newcastle.edu.au

${ }^{3}$ School of Engineering, Design and Built Environment, Western Sydney University, NSW, Australia, M.Hardie@westernsydney.edu.au
} 
Builders often deal with diverse environmental factors and engage in monotonous and stressful jobs (Boatman et al., 2012). Many employment circumstances are itinerant and unreliable, making it easier to lay off workers at short notice (European Social Partners, 2007). The sector also has demanding work tasks, long working hours and sometimes unfeasible implementation terms (Beswick et al., 2007). Such features can have a significant effect on the physical and emotional well-being of the builders. A major study found that work-related stresses could lead to health problems among construction workers (Wang et al., 2017). To fully understand their effect on safety and well-being, it is essential to assess the impact of psychosocial stressors and psychosocial risk factors (PRFs) that help mitigate work-place accidents, avoid illness and enhance profitability (Boschman et al., 2013). Psychosocial influences, as the word implies, reflect emotional and physiological features and the immediate environment. The International Labour Office defines psychosocial factors related to work as 'employment and career experience,' the essence of duties, organisational conditions and skills of workers, preferences, culture, personal extra-work issues that may affect security, job performance and job satisfaction through understanding and experience' (Burki, 2018).

This research aimed to examine factors related to NSW psychosocial and mental wellbeing conditions in the construction industry. The paper started with a literature review. The research methodology was then explained that how the research was conducted and data was collected. The results of the data analysis were discussed in the following section. Last but not least, limitations of the research and recommendations for future work were presented at the end of the paper.

\section{LITARATURE REVIEW}

\subsection{DEFINITION OF PSYCHOSOCIAL HAZARDS AND RISKS}

Stress as a construct has been clarified across many different schools of thinking. Job dissatisfaction can be characterised as mental and physiological reactions to workers' responsibilities. These reactions are psychological (cognitive, physiological, and emotional), these reactions may lead to poor health of workers. Stress is captured as a response, which captures psychological, physiological and emotional aspects of the job. All vital aspects of human health include the workplace, climate, and job nature (Marmot and Wilkinson, 2006).

The International Labour Organization (ILO) mentioned psychosocial risks could include worker relationships, job description, content, labour management and organisation. In various academic writings, emotional exhaustion is defined as physical, mental and emotional deprivation due to long-term commitment to adverse or traumatic conditions for workers. Such interactions are forms of interaction that impact workers' well-being (Schaufeli and Greenglass, 2001).

\subsection{PSYCHOSOCIAL HAZARD AND Risk FACTORS IN CONSTRUCTION}

Psychosocial hazard and risk factors are characterised by work outcomes like financial, execution factors (Beswick et al., 2007); as well as positions in the company such as under-use of jobs or unchanged activity (Goldenhar et al., 1998). Environmental implications such as unusual turnover of employees and inadequate communication because of the transitional nature of construction may also affect work outcomes. (Lunt et al., 2008). 
In the construction industry, psychosocial problems may be caused by tight deadlines, lack of knowledge, or adverse working climate. The workplace can also pose unknown hazards for construction practices, new products, and chemicals. The transition to subcontracting and specialisation (including multiple influences in the same workplace) shifts existing balances. A proper description of occupational mental well-being is essential to recognise possible hazards.

\subsubsection{Finance-related Issues}

Workers can be influenced by financial expenditure to support their families and themselves. One study found that the most significant stressor is financial difficulties. They influence a worker's performance and consequently, their psychological state (Glasscock et al., 2006). Building workers (especially in developing countries) have low pay, wage payment delays, and unpaid overtime (Safe Work Australia, 2011).

\subsubsection{Long Working Hours}

Builders start working earlier than other workers (Dong, 2005). They also have higher chances of multiple jobs and constantly changing jobs. The positive link between long hours, irregular schedules and work injuries was established. This partnership kept after controlling for confounders. Such results suggest that long hours and unpredictable schedules influence employee psychology and damage employee health (Dong, 2005). Long working hours of up to 13 hours or even longer can lead a worker to physical and mental exhaustion (Safe Work Australia, 2011), primarily when working under severe climatic conditions such as extreme heat or extreme cold (Bust and Gibb, 2006). Exhaustion affects a construction worker's psychological well-being.

Overtime-related pressure and exhaustion can affect the worker's ability to remain healthy in the workplace. Longer hours do not necessarily mean higher output. Labour hours are counterproductive above a particular "full production" and can even reduce efficiency. Dong's 2005 research was conducted to identify working hours and schedules for a nationally representative U.S. construction worker (Dong, 2005).

\subsubsection{Workplace Conditions}

Poor workplace conditions in some countries can cause psychological worker health problems. Research by Arboleda and Abraham (2004) found that construction workers forced to work under poor physical conditions experienced considerably more discomfort, affecting their $\mathrm{OH} \& \mathrm{~S}$ status. In the Gulf Cooperation Council (GCC) nations, Sonmez et al. (2011) researched human rights and health disparities among construction workers. They found that inhuman working and living conditions created severe health and safety problems. Weak working conditions include lack of hygiene and lack of construction site operation.

\subsubsection{Work Stress and Work Overload}

Bernaards et al. (2006) evaluated the correlation between physically and mentally conditions in a Dutch population. In the sedentary workforce, the "dose-response correlation between strenuous physical activity and poor general health" was found to be most vital. Another result showed that hard leisure physical exercise once or twice a week has a lower risk of long-term absenteeism, such as more than 21 days or three weeks. It was concluded that a sedentary population benefited more from extreme recreation than non-sedentary employees and that the potential of physical activity to avoid possible 
psychological and physical health issues, as well as long-term absenteeism may be beneficial among employees.

\subsubsection{Shift Rotation}

Van Amelsvoort et al. (2004) studied the differences between three-shift workers' psychological well-being and their work-family tensions. Results suggested that a backwards-looking schedule is related to a greater need for rehabilitation and poor overall health. The authors concluded that optimising shift-work plans in terms of shift rotation appears to be a promising solution to minimising the detrimental effects of shift work. The study was based on a Maastricht cohort study, where $\mathrm{N}=12,095$ respondents, 95 employees, and 681 employees were working in three shifts, retroactive rotating jobs. (Van Amelsvoort et al., 2004).

\subsubsection{Relations with Workmates}

Social-psychological factors include a welcoming workforce and worker relationships (e.g., "team spirit" and "good working relationship"), The latter is "much more important for productivity". Construction workers are engaged with a crew or project for a limited period. Staff who were clustered in crews and got along well had more substantial safety records (Kazaz and Ulubeyli, 2007).

\subsubsection{Cultural Adjustment}

Loosemore et al. (2010) examined the nature of cultural diversity on Australian building sites and their impact on workers. Findings found that most respondents had a reasonable degree of intercultural interaction with other cultural groups. However, ethnic identities are based on friendship groups for most operatives, and many workers do not try to connect outside their ethnic culture.

\section{RESEARCH METHODOLOGY}

After identifying these psychosocial hazards and risk factors in the construction industry, a questionnaire survey was conducted with practitioners from two private construction companies and one government department having construction project management experience in NSW. Research ethic approval was granted before the data collection started. Only those people who gave their informed consent were included in the project. If they decided to not participate, they could withdraw from the project at any time without giving a reason and they had the option of withdrawing their data up to point of publication. Around two hundred responds were collected. After manually checking the complement situation of those responds, 100 valid responds were selected to do the data analysis. Respondents included project managers (employers), contractors, experts and consultants, and workers. Table 1 presents the percentage of respondents.

Table 1. Percentage of respondents

\begin{tabular}{lc}
\hline \multicolumn{1}{c}{ Respondents } & Percentage \\
\hline Project managers & $5 \%$ \\
Contractor managers & $20 \%$ \\
Experts and consultants & $25 \%$ \\
Workers & $50 \%$ \\
\hline
\end{tabular}




\section{DATA ANALYSIS AND DISCUSSIONS}

Data were analysed and clustered by the frequency. Figure 1 presented items that concerned the various aspects of the current job. The results showed that most of respondents did not have a choice in deciding what they do at work, but they have a say in their own work speed. Some of the time, respondents have some say over the way they get the job done.

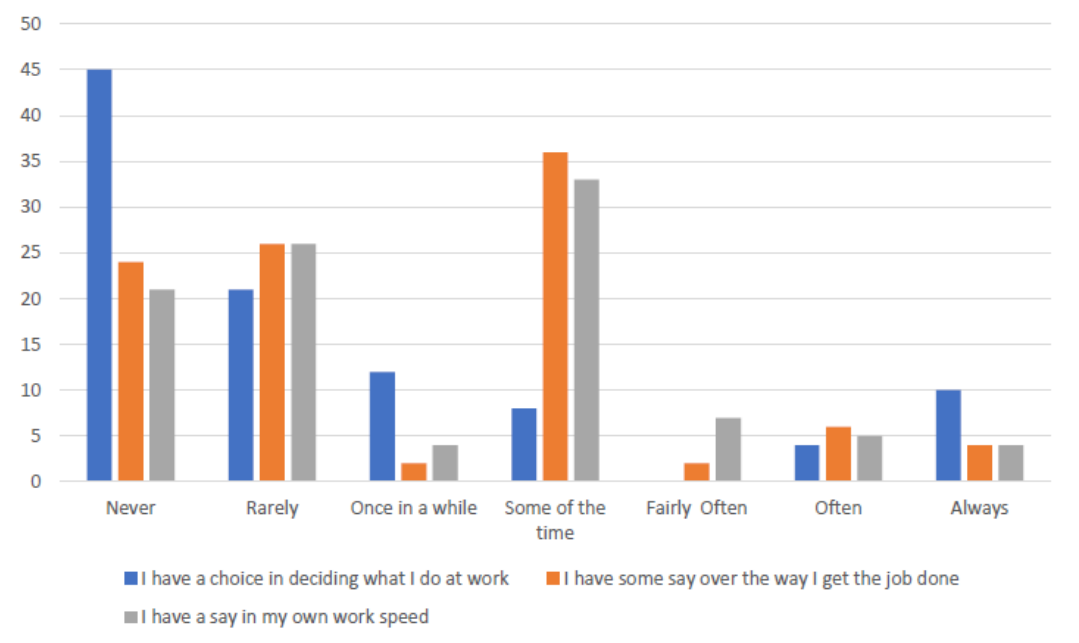

Figure 1: Items that concern various aspects of their current job

Figure 2 provided data on workers who have been pressured in their current job. 'I am pressured to work long hours' can be seen highest at 'Often' (56). 'I have unachievable deadlines' and 'I have unrealistic time pressures' can both be seen reaching their maximum at 'Some of the time' $(63,57$, respectively), with 'I have to neglect some tasks because I have too much to do' being highest at 'Once in a while' (69). The results suggested that most workers are 'Often' pressured to work long hours with unachievable deadlines. This can cause high stress levels due to lack of sleep and less free time performing hobbies. If workers are always pressured to work long hours, then the stress levels will continue to rise and thus lead to depression overtime.

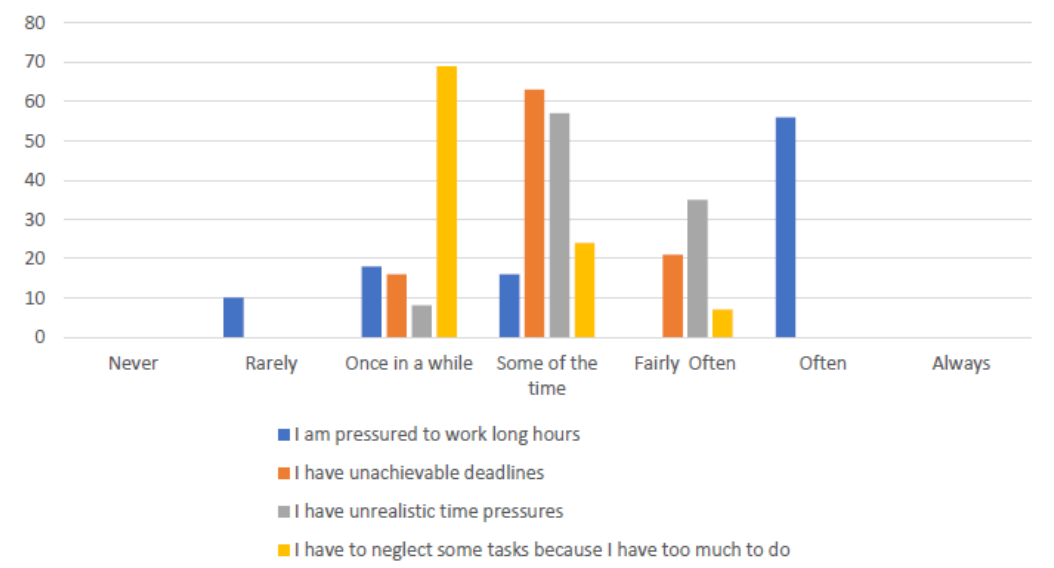

Figure 2: Items concern the amount of time pressure have in their current job

The data from Figure 3 outlined the support that a worker receives from a co-worker. 'I can rely on my co-workers to help me out with a work problem' and 'If the work gets difficult, my co-workers will help me' can be seen to be highest at 'Some of the time' 
$(59,42$, respectively). This indicated that although co-workers cannot be helpful all the time, but some of the time workers can help each other at work. However, 'I get the help and support I need from my co-workers' and 'My co-workers are willing to listen to my work-related problems' reach their greatest at 'Once in a while' (37, 39, respectively). This indicated that construction workers normally could only hold their feelings to themselves without mental support from co-workers. This increased the chance of mental issues if problems keep building up.

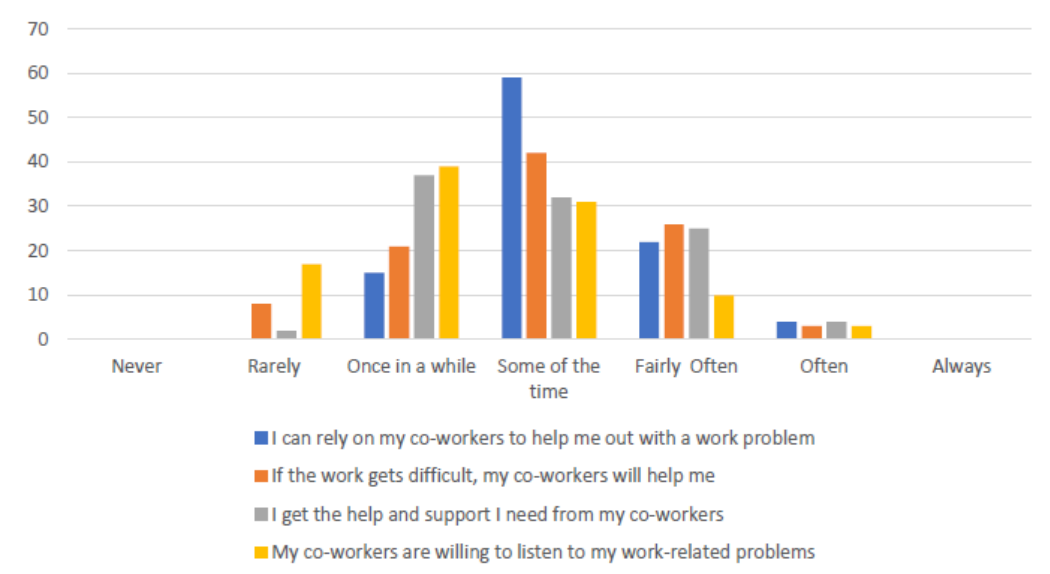

Figure 3: Support received from co-workers.

Figure 4 presented the relationship of a worker and their supervisor. 'I feel that my supervisor values my contributions to this organisation' reaches its highest at 'Some of the time' (41). However, 'My supervisor gives me sufficient credit for my hard work' peaks at 'Once in a while' (47), while 'My supervisor encourages me in my work with praise and thanks' is also highest at 'Some of the time' (48). This indicates that workers may need more praise and credits recognized from their supervisor when completing hard tasks in order to encourage them in continuous work.

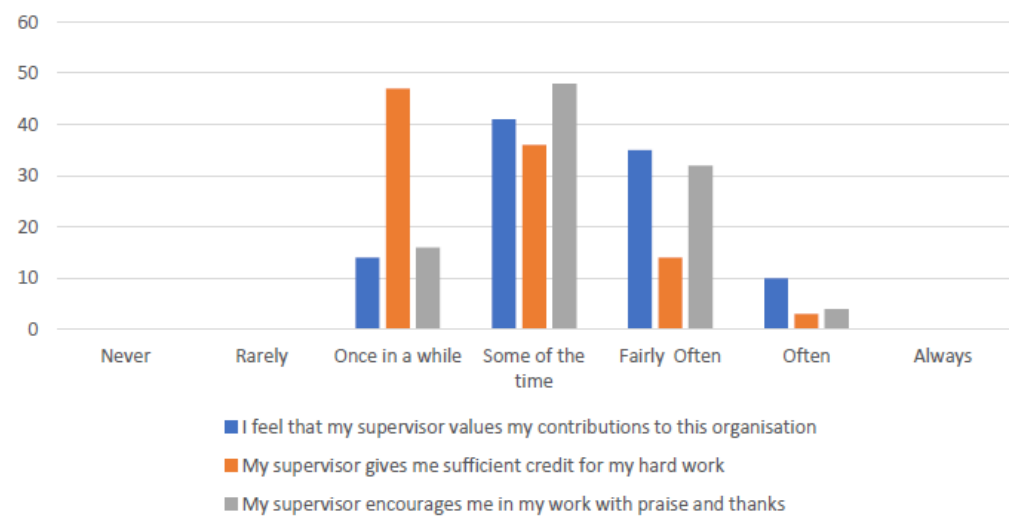

Figure 4: Relationship with supervisor

Figure 5 showed the various relationship conflicts within a workgroup. 'Processes are applied consistently in your workgroup' reaches a maximum of 64 at 'Often', while 'Processes are free from bias in your workgroup' reaches a maximum of 58 at 'Fairly Often'. This indicates that works on sites can be consistent and good for experienced workers to finish their job within the required quality and time. 'Employees in your workgroup are able to express their views and feelings during those processes' and 'Processes are based on accurate information about your workgroup' both peak at 
'Always' (75, 66, respectively). This indicates the consistent results with the other relationship conflicts within a workgroup. Because works on sites are consistent, work processes are transparent to workers, and they can have a say in their work.

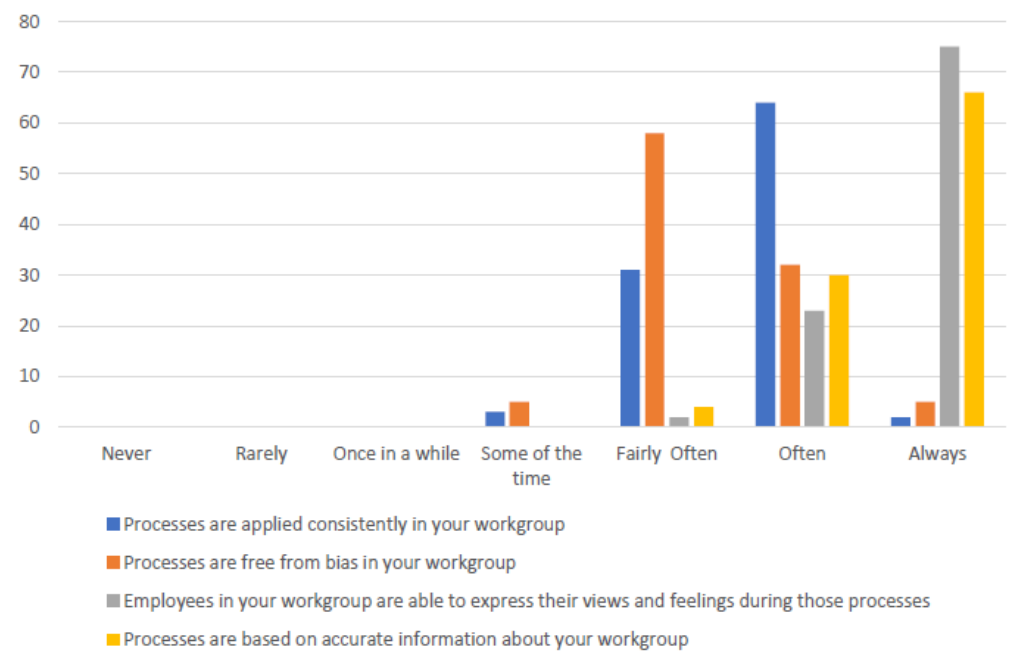

Figure 5: Relationship conflicts in the workgroup

In Figure 6, frequency of different bully behaviours at work were analysed. 'Verbal abuse' and 'Sabotage of your work' peak at 'Rarely' (46, 57, respectively). At the same time, 'Threats of punishment for no reason', 'Ridicule and being put down', 'Offensive messages' and 'Persistent and unjustified criticism' reach their maximum at 'Never' (58, $52,43,62$, respectively). However, 'Exclusion or isolation from workplace activities' reaches' is most common 'Monthly' (32), while 'Subjects of gossip or false, malicious rumours' happen 'Weekly' (42) and 'Humiliation through gestures, sarcasm, criticism or insults' happen 'Almost daily' (55). This indicates that verbal abuse, threats and being ridiculed very rarely occurred within the workplace. However, criticism, gossip or false rumours was consistently occurring weekly and sometimes daily. All these bully behaviours could increase mental problem of construction workers, which would cause work health and safety problems on construction sites.

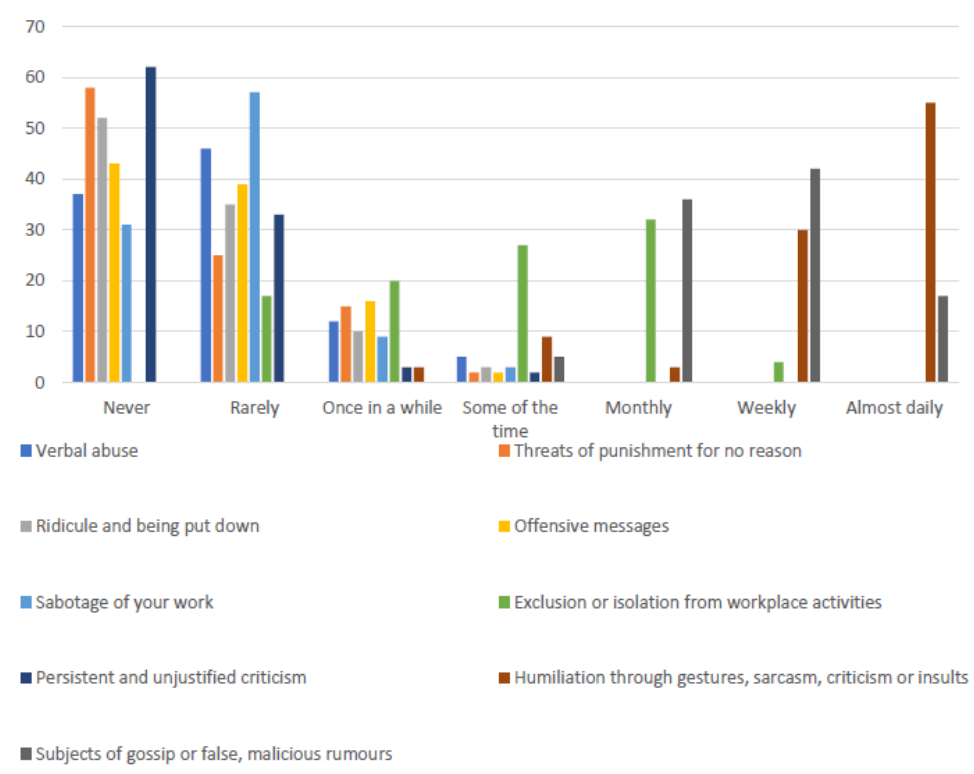

Figure 6: Bully behaviours at work 


\section{CONCLUSIONS}

The research paper aimed to educate readers about some of the factors that influence psychosocial hazards and mental health in the construction industry in NSW. It was critical to survey different companies to examine how psychosocial hazards affect workers' mental health in the NSW construction industry.

The data indicates that most workers are often pressured to stay back and work long hours, which then lead to workers being very frequently tired. Further research must be done to investigate the correlation between being tired and how they can affect the stress levels of a construction worker. The results showed that most of respondents did not have a choice in deciding what they do at work, but they have a say in their own work speed. The results suggested that most workers are 'Often' pressured to work long hours with unachievable deadlines. This can cause high stress levels due to lack of sleep and less free time performing hobbies. If workers are always pressured to work long hours, then the stress levels will continue to rise and thus lead to depression overtime. Although coworkers cannot be helpful all the time, but some of the time workers can help each other at work. Construction workers normally could only hold their feelings to themselves without mental support from co-workers. This increased the chance of mental issues if problems keep building up. Workers may need more praise and credits recognized from their supervisor when completing hard tasks in order to encourage them in continuous work. 'Exclusion or isolation from workplace activities' was found to be a very worrying occurrence for some workers, other negative relational behaviours were also reported as widespread. Verbal abuse, threats and being ridiculed very rarely occurred within the workplace in the past six months. However, criticism, gossip or false rumours was consistently occurring weekly and sometimes daily. All these bully behaviours could increase mental problem of construction workers, which would cause work health and safety problems on construction sites. Hopefully, spreading awareness on these psychosocial hazards can slowly improve the mental health of construction workers in NSW and decrease the overall suicide rates. The limitation of this research was to conduct the research in NSW, Australia, due to geographical focus of primary data collection. The suggestions for future research can be; (1) To extend the research to other regions in Australia, (2) To compare results in different regions and to see whether construction practitioners react differently on psychosocial hazards.

\section{REFERENCES}

Arboleda, C.A. and Abraham, D.M., 2004. Fatalities in trenching operations - analysis using models of accident causation. Journal of Construction Engineering and Management, 130(2), pp. 273-280.

Bernaards, C.M., Jans, M.P., Van den Heuvel, S.G., Hendriksen, I.J., Houtman, I.L., and Bongers, P.M., 2006. Can strenuous leisure time physical activity prevent psychological complaints in a working population? Occupational and Environmental Medicine, 63(1), pp. 10-16.

Beswick, J., Rogers, K., Corbett, E., Binch, S. and Jackson, K., 2007. An analysis of the prevalence and distribution of stress in the construction industry. Health and Safety Executive, pp.1-81.

Boatman, L., Chaplan, D. and Teran, S., 2012. Creating the climate for making ergonomic changes, Center for Construction Research and Training, Silver Spring.

Boschman, J.S., van der Molen, J.K., Sluiter, and Frings-Dresen, M.H., 2013. Psychosocial work environment and mental health among construction workers, Applied Ergonomics, 44(5), pp. 748-755.

Burki, T., 2018. Mental health in the construction industry. The Lancet Psychiatry, 5(4), pp. 303.

Bust, P.D. and Gibb, A.G.F., 2006. Managing construction health and safety: Migrant workers and communicating safety messages, Safety Science, 46(4), pp. 585-602. 
Dong, X.W., 2005. Long workhours, work scheduling and work-related injuries among construction workers in the United States, Scandinavian Journal of Work, Environment and Health, 31(5), pp. 329335.

European Social Partners 2007, Framework agreement on harassment and violence at work, Brussels: European Social Partners.

Glasscock, D.J., Rasmussen, K., Carstensen, O., and Hansen, O.N., 2006. Psychosocial factors and safety behaviour as predictors of accidental work injuries in farming, Work \& Stress: An International Journal of Work, Health \& Organisations, 20(2), pp. 173-189.

Goldenhar, L.M., Swanson, N., Hurrell J.J., Ruder, A., Deddens, J., 1998. Stressors and adverse outcomes for female construction workers, Journal of Occupational Health Psychology, 3(1), pp. 19-32.

Kazaz, A. and Ulubeyli, S., 2007. Drivers of productivity among construction workers: A study in a developing country, Building and Environment, 42(5), pp. 2132-2140.

Loosemore, M., Phua, F., Dunn, K. and Ozguc, U., 2010. Managing cultural diversity in Australia construction sites, Construction Management and Economics, 28(2), pp. 177-188.

Lunt, J., Bates, S., Bennett, V. and Hopkinson, J., 2008. Behaviour change and worker engagement practices within the construction sector. HSE (Health and Safety Executive) Research Report (RR)660.

Marmot, M. and Wilkinson, R.G. 2006. Social determinants of health, Oxford: Oxford University Press, 2nd ed., Denmark.

Safe Work Australia, 2011. How to manage work health and safety risks - Code of practice. [Online] Available from: https://www.safeworkaustralia.gov.au/doc/model-code-practice-how-manage-workhealth-and-safety-risks.

Schaufeli, W.B. and Greenglass, E.R., 2001. Introduction to special issue on burnout and health, Psychology Health, 16, pp. 501-510.

Sonmez, S., Apostolopoulos, Y., Tran, D., and Rentrope, S., 2011. Human rights and health disparities for migrant workers in the UAE, Health and Human Rights, 13(2), pp. 17-35.

Van Amelsvoort, L.G.P.M., Jansen, N.W.H., Swaen, G.M.H., and Van den Brandt, P.A., 2004. Direction of shift rotation among three-shift workers in relation to psychological health and work-family conflict, Scandinavian Journal of Work, Environment and Health, 30(2), pp. 149-156.

Wang, C., Mohd-Rahim, F.A., Chan, Y.Y., and Abdul-Rahman H., 2017. Fuzzy mapping on psychological disorders in construction management, Journal of Construction Engineering and Management, 143(2), p. 04016094. 